obtained is similar to those of other investigators as noted in the review of Doolan et al. (1962).

In analysing the data of $\mathrm{Kim}$ et al. two possibilities are suggested for the discrepancy. Firstly the normal values they report for inulin clearance-that is, $95 \pm 17 \mathrm{ml} / \mathrm{min}$ for men and $94 \pm 16$ for women-are considerably below the $124 \pm 26$ for men and $109 \pm 13$ for women published by Homer Smith (1956). Secondly, it is possible that their patients were not in a steady state after preclearance water loading. It has been shown by Porter et al. (1966) that sudden augmentation of urine flow may "wash out" a reservoir of creatinine, presumably from renal tubular cells. The increased rate of tubular transit tends to make the $U / P$ ratio for creatinine less at any one time, creating a more favourable gradient for creatinine excretion. The net effect during the period of "wash out" would be for creatinine clearance to overestimate simultaneously measured inulin filtration rate.

It has been well established that creatinine can be secreted by the renal tubules particularly if the glomerular filtration rate is decreased-that is, $\mathrm{C}_{\mathrm{cr}}>\mathrm{C}_{\mathrm{in}}$ (Brod and Sirota, 1948; Miller et al., 1952). This is usually true only if the serum creatinine is measured as true creatinine and not as total chromogen. When the latter is used (most clinical laboratories and autoanalyzer techniques) the addition of non-creatinine chromogens increase the measured serum creatinine and cancels out the urinary creatinine contributed by tubular secretion. The absolute amount of non-creatinine chromogen stays relatively constant as the filtration rate falls and true creatinine rises with renal disease. Thus the creatinine clearance tends to increase in relation to inulin when tubular secretion is maximal (low filtration rate) and non-creatinine chromogen is a small fraction of serum creatinine. Skov (1970) showed that with severe renal disease $C_{c r}$ may overestimate $C_{i n}$. Twenty-two of his patients had $C_{i n}$ less than $5 \mathrm{ml} / \mathrm{min}$ while our series had only four patients below $20 \mathrm{ml} / \mathrm{min}$. The low filtration rates of his series no doubt account for the higher $\mathrm{C}_{\mathrm{cr}} / \mathrm{C}_{\text {in }}$ observed.

What was variable in our study were successive inulin or creatinine clearances while in a steady state, and this was true of the normals, the post catheter patients, and those with renal disease. Table II and III summarize these data both in absolute $\mathrm{ml} / \mathrm{min}$ and in perentage. The change in successive creatinine clearance reached as high as $27 \%$ in the
13 patients with inulin clearances $<50 \mathrm{ml} / \mathrm{min}$. It is noteworthy that this is the range of filtration rate found in many patients with various renal diseases and after renal transplantation. If the spontaneous variability of filtration rate is not recognized erroneous conclusions as regards progression of disease or results of therapy may be drawn. Though with a 24-hour clearance of creatinine the variability of successive clearances might be minimized, the urinary excretion of creatinine is also inconstant as Edwards et al. (1969) emphasized. Further, it is obvious that variation in the production or excretion of creatinine cannot explain the inconstancy of inulin clearances.

In 30 of the 39 patients successive $C_{i n}$ and $C_{c r}$ changed in the same direction, increasing 16 times and decreasing 14 times. In the nine instances where $\mathrm{C}_{\mathrm{in}}$ and $\mathrm{C}_{\mathrm{cr}}$ varied in opposite directions the deviations were extremely smallthat is, the values were virtually the same. Thus the change in successive clearances seems to be random.

Brod and Sirota (1948) found that proteinuria enhanced creatinine excretion and thus increased $\mathrm{C}_{c r}$ in relation to $\mathrm{C}_{i n}$. In our series proteinuria was just as common when $C_{i n}$ was less than $\mathrm{C}_{\mathrm{cr}}$ as the converse. Studies by Hilton et al. (1969) support this conclusion.

We wish to express our appreciation for the technical help of Jean Kimsey and the secretarial help of Mrs. Ruth Auch.

\section{References}

Kim, K. E., Onesti, G., Ramirez, O., Brest, A. N., and Swartz, G. (1969). British Medical fournal, 4, 11

Roe, J. H., Epstein, J. H., and Goldstein, N. P. (1949). Fournal of Biological Chemistry, 178, 839 .

Haugen, H. N. (1953). Scandinavian Fournal of Clinical and Laboratory Investigation, 5,48 .

Smith, H. W. (1956). Principles of Renal Physiology, New York, Oxford University Press.

Doolan, P. D., Alpen, E. L., and Theil, G. B. (1962). American fournal of Medicine, 32, 65 .

Porter, G. A., et al. (1966). Circulation, 34, 1005.

Brod, J., and Sirota, J. H. (1948). Fournal of Clinical Investigation, 27, 645 Miller, B. F., Leaf, A., Mamby, A. R., and Miller, Z. (1952). Fournal of Clinical Investigation, 31, 309.

Edwards, O. M., Bayliss, R. I. S., and Miller, S. (1969). Lancet, 2, 1165.

Skov, P. E. (1970). Acta Medica Scandinavica, 187, 419.

Hilton, P. J., Lavender, S., Roth, Z., and Jones, N. F. (1969). Lancet, 2, 1215.

\title{
Oxygen Therapy for Spontaneous Pneumothorax
}

\section{T. C. NORTHFIELD}

\section{British Medical fournal, 1971, 4, 86-88}

\section{Summary}

The rate of absorption of gas from a pneumothorax was studied in 12 patients breathing air and in 10 patients breathing air and a high concentration of oxygen alternately. The mean rate of absorption while breathing air was the same in both groups of patients. In the second group the rate consistently increased during periods of oxygen therapy and decreased again on breathing air. The mean rate of absorption increased fourfold during periods of oxygen therapy. This increase was most pronounced in patients with a large pneumothorax.

Guy's Hospital, London S.E.1

T. C. NORTHFIELD, M.D., M.R.C.P., Senior Medical Registrar

\section{Introduction}

Comroe et al. (1962) pointed out that capillary and venous blood never have gas tensions that add up to total atmospheric pressure. During inhalation of air the total gas pressure in blood from the distal end of a capillary is about $706 \mathrm{~mm}$ $\mathrm{Hg}$, whereas during inhalation of $100 \%$ oxygen it is about $146 \mathrm{~mm} \mathrm{Hg}$. This difference is mainly due to a reduction in partial pressure of nitrogen from $573 \mathrm{~mm} \mathrm{Hg}$ to zero. Though this is accompanied by an increase in the partial pressure of oxygen in arterial blood from 100 to $640 \mathrm{~mm} \mathrm{Hg}$, oxygen utilization in the tissues ensures that the partial pressure of oxygen in end-capillary blood rises only slightly from $40 \mathrm{~mm} \mathrm{Hg}$ to about $53 \mathrm{~mm} \mathrm{Hg}$ (Comroe et al., 1962).

These figures suggest the hypothesis that inhalation of a high concentration of oxygen might increase the rate of absorption of gas from the pleural cavity. A reduction in the total pressure of gases in a pleural capillary would 
increase the pressure difference between it and the pleural cavity. If the rate of absorption of gas from the pleural cavity were proportional to this pressure difference, then oxygen therapy should increase the rate of absorption.

\section{Patients and Methods}

The rate of absorption was studied in two groups of patients with a spontaneous pneumothorax. The first group was studied retrospectively. It contained 12 patients who had been treated in hospital by bed rest and observation alone. All were male, aged 17 to 51 (mean 25) years. The second group was studied prospectively. It contained 10 patients who were treated intermittently with high concentration oxygen for periods of 9 to 38 hours at a time. This procedure was thought to be in the interests of the patients concerned. During the intervening periods the patients breathed air, thus acting as their own controls. Nine of them were male and one female, aged 15 to 67 (mean 34) years.

Oxygen was given by means of a Polymask, a high concentration being obtained, on the high flow principle, by connecting the Polymask via a Y-connexion to two adjacent sources of piped oxygen, so as to deliver oxygen at a rate of 16 litres per minute. With this high rate of flow the Polymask was apt to leak from the area around the input tube, but this could usually be prevented by reinforcing this area with adhesive plaster before use. During periods of oxygen treatment the mask was worn continuously, day and night, except for meals and at visiting times.

For the prospective study daily chest $x$-ray films were taken on full inspiration. The inner edge of the chest wall and the outer edge of the lung were traced on transparent paper. This was then superimposed on graduated graph paper and the area corresponding to the pneumothorax cavity was measured. The rate of absorption was expressed in $\mathrm{cm}^{2} / 24$ hours. All measurements were carried out without previous knowledge of which tracings corresponded to oxygen therapy. Observer variation was small, measurements of 22 tracings by two separate observers deviating from the mean value by an average of $1.6 \%$ and by a maximum of $5 \%$.

Measurements of oxygen and carbon dioxide tension were made with a Radiometer electrode system.

\section{Results}

Fig. 1 shows the rates of absorption in both groups of patients. While breathing air the mean rate in group 2 $\left(4.8 \mathrm{~cm}^{2} / 24\right.$ hours) was the same as that in group 1 . While breathing oxygen, however, the rate of absorption in group 2 increased by a factor of 3.7 to a mean value of 17.9 $\mathrm{cm}^{2} / 24$ hours $(\mathrm{P}<0.01)$. The rate in those with an initial pneumothorax size of more than $30 \%$ of the pleural cavity (taken as more than $75 \mathrm{~cm}^{2}$ ) increased by a factor of 5.2 to a mean value of $25.2 \mathrm{~cm}^{2} / 24$ hours, whereas in those with an initial pneumothorax size of less than $30 \%$ it increased by a factor of 2.2 to a mean value of 10.4 $\mathrm{cm}^{2} / 24$ hours $(\mathrm{P}<0.01)$. While breathing air the mean rate of absorption in both groups taken together was $5.1 \mathrm{~cm}^{2} / 24$ hours in those having an initial pneumothorax size of more than $30 \%$, and this was not significantly different from the mean rate $\left(4.6 \mathrm{~cm}^{2} / 24\right.$ hours) in those having a small pneumothorax.

Fig. 2 shows the rates of absorption in the 10 patients in group 2 during alternating periods of air and oxygen. In individual patients the rate consistently rose on breathing oxygen and then fell again on breathing air. The negative rate of absorption found in one patient during the initial period of breathing air probably indicated a continuing leak of air into the pleural space. The calculated time for full re-expansion for the patients in group 2 varied from 8 to
45 (mean 22.5) days with continuous inhalation of air, and from 3 to 8 (mean 5.4) days with daily oxygen therapy.

None of the patients in group 2 developed radiological evidence of oxygen toxicity. The only complications encountered were soreness of the bridge of the nose from the pressure of the Polymask, which could be alleviated by putting a small dressing on this area, and a tendency for the Polymask to tear as a result of the high flow rate. Both of these disadvantages can be avoided by using an M.C. mask, but this probably gives a lower inspired oxygen concentration (Leigh, 1970).

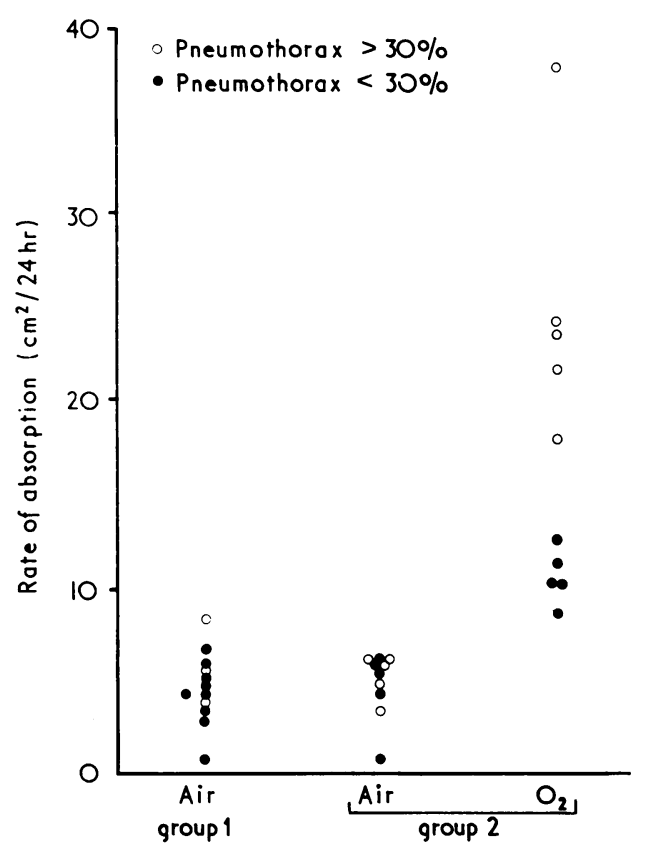

FIG. 1-Mean rate of absorption of gas from the pleural cavity during inhalation of air (groups 1 and 2) and oxygen (group 2 only).

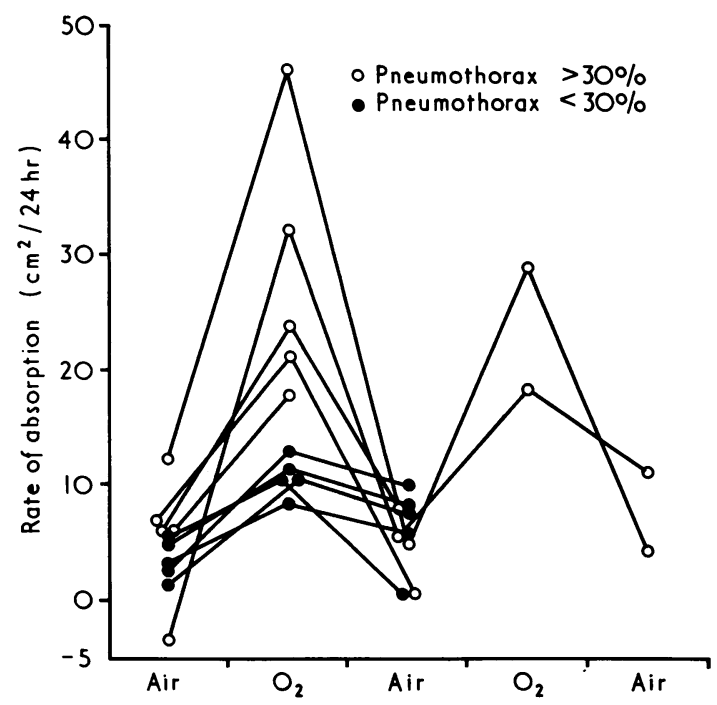

FIG. 2-Rates of absorption of gas during alternating periods on and off oxygen therapy (group 2 only.)

Measurements of oxygen and carbon dioxide tension were carried out in a 26-year-old man with no evidence of generalized lung disease. On oxygen therapy the oxygen tension in femoral arterial blood rose from 82 to $360 \mathrm{~mm} \mathrm{Hg}$, in venous blood taken from the antecubital fossa it rose from 26 to $36 \mathrm{~mm}$ $\mathrm{Hg}$, and in the pleural cavity it rose from 56 to $174 \mathrm{~mm} \mathrm{Hg}$. Carbon dioxide tension fell from 40 to $36 \mathrm{~mm} \mathrm{Hg}$ in arterial blood, from 53 to $46 \mathrm{~mm} \mathrm{Hg}$ in venous blood, and from 40 to $34 \mathrm{~mm} \mathrm{Hg}$ in the pleural cavity. 


\section{Discussion}

"The treatment of spontaneous pneumothorax is a rather unhappy story. Many methods have been and are still being tried, but none is entirely satisfactory" (British Medical fournal, 1965). There is general agreement that a tension pneumothorax must be treated as an emergency by inserting a wide-bore needle or intercostal catheter (Davies, 1969), which can be connected subsequently to an underwater seal or to a valve (Knight, 1967). There is, however, considerable controversy about the treatment of cases not under tension. Some believe that, in the absence of respiratory distress or underlying lung disease, the patient can be followed up as an outpatient while continuing at work in most cases (Stradling and Poole, 1966; Davies, 1969). Stradling and Poole (1966) successfully managed $80 \%$ of their patients in this way. Some believe that an intercostal catheter should be inserted in those with a large pneumothorax (Horne, 1966; British Medical fournal, 1968; Lennox, 1970), and others that catheter drainage or some other surgical procedure should be carried out in almost all cases (Ruckley and McCormack, 1966; Thompson and Bailey, 1966).

The principal reason put forward for inserting an intercostal catheter in those with a large pneumothorax is to shorten the course of treatment (Lennox, 1970). The average length of hospital stay in several large series treated by intercostal catheter varied from 5 to 30 days, with a mean of 13 days (Klassen and Meckstroth, 1962; Smith and Rothwell, 1962; Killen and Jackson, 1963; Ransdell and McPherson, 1963; Withers et al., 1964; Lynn, 1965; Timmis et al., 1965; Thompson and Bailey, 1966). There was an average failure rate of $19 \%$. In one series of 88 patients nine died (Ransdell and McPherson, 1963).

In the present series oxygen therapy resulted in a fourfold increase in the mean rate of absorption. Further study would be necessary to check whether a similar increase in absorption could be achieved with a lower flow rate of oxygen. The observation that the effect of oxygen was less pronounced in patients with a small pneumothorax may be due to the fact that in these patients the two layers $o^{c}$ the pleura tended to come into contact in parts of the pleural space, so that the surface area available for absorption was reduced.

The calculated time for full re-expansion with daily oxygen therapy ranged from three to eight days, with a mean of five days. The patient can presumably be discharged from hospital either at this stage or else before full re-expansion has been obtained. This method of treatment, therefore, compares favourably with the use of an intercostal catheter as a method of shortening hospital stay. There were no failures in the present study, and no serious complications. Though high concentration oxygen at atmospheric pressure can have a toxic effect on the lungs, this seems to be limited to patients receiving it continuously for 24 hours daily, and the effects of intermittent exposure are not cumulative (Pratt, 1965). Administration was intermittent in the present study, and none of the patients developed radiological changes suggestive of oxygen toxicity. The inspired oxygen concentration was not measured, but it is very unlikely to have been as high as $100 \%$, though it was probably higher than the 50 to $60 \%$ obtained with the Polymask using a lower flow rate of eight litres per minute (Leigh, 1970).

It is clearly important that treatment with high concentration oxygen should be avoided in patients with respiratory failure and in those with a tension pneumothorax. This method of treatment should probably be limited to the common primary type of spontaneous pneumothorax occurring in the absence of any generalized lung disease.

My thanks are due to the consultant staff of Guy's Hospital for allowing me to study patients admitted under their care.

\section{References}

British Medical fournal, 1965, 1, 1262.

British Medical fournal, 1968, 1, 720 .

Comroe, J. H., Forster, R. E., Dubois, A. B., Briscoe, W. A., and Carlsen, E. (1962). The Lung, 2nd edn., p. 311 . Year Book Medical Publishers, Chicago.

Davies, P. D. B. (1969). Practitioner, 203, 767.

Horne, N. W. (1966). British Medical fournal, 1, 281.

Killen, D. A., and Ja:kson, L. M. (1963). Fournal of the Tennessee Medical Association, 56, 439

Klassen, K. P., and Meckstroth, C. V. (1962). Fournal of the American Medical Association, 182, 1.

Knight, R. K. (1967). Lancet, 1, 190.

Leigh, J. M. (1970). Anaesthesia, 25, 210

Lennox, S. C. (1970). British fournal of Hospital Medicine, 3, 893.

Lynn, R. B. (1965). Diseases of the Chest, 48, 251.

Pratt, P. C. (1965). Annals of the New York Academy of Science, 121, 809. Ransdell, H. T., and McPherson, R. C. (1963). Archives of Surgery, 87, 1023. Ruckley, C. V., and McCormack, R. J. M. (1966). Thorax, 21, 139.

Smith, W. G., and Rothwell, P. P. G. (1962). Thorax, 17, 342.

Stradling, P., and Poole, G. (1966). Thorax, 21, 145.

Thompson, H. T., and Bailey, R. R. (1966). New Zealand Medical fournal, 65, 101.

Timmis, H. T., Virgilio, R., and McClenathan, J. E. (1965). American Fournal of Surgery, 110, 929 .

Withers, J. N., Fishback, M. E., Kiehl, P. V., and Hannon, J. I.. (1964) American fournal of Surgery, 108, 772.

\section{MEDICAL MEMORANDA}

\section{Emergency Hypophysectomy in Pregnancy After Induction of Ovulation}

\section{T. KAJTAR, GERALD H. TOMKIN}

British Medical fournal, 1971, 4, 88-90

Since the introduction of human gonadotrophin therapy by Gemzell et al. (1958) it has been possible to induce ovulation

\section{Royal Victoria Hospital, Belfast BT12 6BA}

T. KAJTAR, M.B., M.R.c.o.G., Clinical Research Fellow in Obstetrics and Gynaecology

GERALD H. TOMKIN, M.D., M.R.C.P.(LOND., IRE.), Senior Registrar in Endocrinology in patients suffering from hypogonadotrophic states, including those caused by pituitary tumours. This paper reports the sudden increase in size of an unsuspected pituitary tumour during pregnancy after the successful induction of ovulation with human menopausal gonadotrophin (Pergonal).

\section{Case History}

The patient was first seen in April 1967 at the age of 30 years with a history of secondary amenorrhoea for 14 months. The menarche was at 15 years and menstruation was regular until she started nursing at the age of 19 . Menstruation then became irregular and there were periods of amenorrhoea lasting up to 12 months. Full physical examination showed nothing abnormal apart from a minor degree of hypo-oestrogenization of the vaginal wall.

Investigations.-Haemoglobin $1 \mathrm{j} \cdot 6 \mathrm{~g} / 100 \mathrm{ml}$; serum cholesterol $302 \mathrm{mg} / 100 \mathrm{ml}$; radioactive triiodothyronine red cell uptake $13.8 \%$ (normal 11.5 to $19.5 \%$ ); protein bound iodine $6.4 \mu \mathrm{g} / 100 \mathrm{ml}$; radioactive iodine ${ }^{\left({ }^{31}\right.} \mathrm{I}$ ) neck uptake at 24 hours $13.8 \%$ (within the 